\title{
Influence of Surface Tension and Evaporation on Melt Dynamics of Aluminum Alloys for Laser Powder Bed Fusion
}

\author{
Marko Bärtl, Xiao Xiao (D), Jürgen Brillo, and Frank Palm
}

\author{
Submitted: 9 September 2021 / Revised: 25 November 2021 / Accepted 4 January 2022 / Published online: 31 January 2022
}

\begin{abstract}
One of the most important factors during Laser Powder Bed Fusion is a robust and stable process to generate reproducibly dense and crack-free components with the same homogenous and fine-grained microstructure. Among other factors, surface tension influences the robustness of this process. Three aluminum alloys were investigated by means of 3D laser printing with respect to their ability to form lightweight and high-performance structures. The alloys include two Al-Cr based alloys (Zicromal@: AlCr-Zr-Mn, Scancromal ${ }^{\circledR}:$ Al-Cr-Sc-Zr) and an Al-Mg based alloy (Scalmalloy ${ }^{\circledR}$ : Al-Mg-Sc-Mn-Zr). The surface tensions of their liquid melts were measured by means of the oscillating droplet method in electromagnetic levitation. Scalmalloy ${ }^{\circledR}$ exhibited a surface tension that was by 3-8\% smaller than the other two alloys, over a temperature range of $500 \mathrm{~K}$ above their liquidus temperature; the evaporation analysis showed that Scancromal ${ }^{\circledR}$ exhibits significantly less evaporation compared to the other two alloys by an order of magnitude. During the Laser Powder Bed Fusion process, Scalmalloy ${ }^{\circledR}$ presented the most unstable melt dynamics, and Scancromal ${ }^{\circledR}$ appeared to be more robust and stable with less weld spatters and negligible dust deposition, as evidence from the high-speed video observations. The results support the idea that surface tension and evaporation are potentially crucial factors influencing the melt dynamics and also demonstrate the capability of additive manufacturing that produces customized aluminum alloys for aerospace applications.
\end{abstract}

Keywords additive manufacturing, aluminum alloys, electromagnetic levitation, evaporation, laser powder bed fusion (L-PBF), melt dynamics, surface tension

\section{Introduction}

To continue the successful exploration of space (e.g., "return to the moon" and "first visit to Mars"), additive manufacturing will be essential and necessary, which enables lightweight and high-performance structures. Customized highstrength aluminum alloys will be some of the most important

This invited article is part of a special issue in the Journal of Materials Engineering and Performance entitled "Space and Aerospace Exploration Revolution: Metal Additive Manufacturing." The issue was organized by Shahrooz Nafisi, Relativity Space; Paul Gradl, NASA Marshall Space Flight Center; Douglas Hofmann, NASA Jet Propulsion Laboratory/California Institute of Technology; and Reza Ghomashchi, The University of Adelaide, Australia.

Marko Bärtl, Airbus Central Research \& Technology, Airbus Defence and Space GmbH, 82024 Taufkirchen, Germany; and Institute of Materials Science, Universität der Bundeswehr München, 85579 Neubiberg, Germany; Xiao Xiao and Jürgen Brillo, Institut für Materialphysik im Weltraum, Deutsches Zentrum für Luft- und Raumfahrt (DLR), 51170 Köln, Germany; Frank Palm, Airbus Central Research \& Technology, Airbus Defence and Space GmbH, 82024 Taufkirchen, Germany. Contact e-mail: xiao.xiao@dlr.de. manufacturing approaches for future satellites and space vehicles. As currently alloy performance is inadequate, new materials need to be designed, developed, tested, and validated. The aluminum alloys used in additive manufacturing (Laser Powder Bed Fusion, L-PBF) at the present time have mostly been adopted from conventional manufacturing such as casting (e.g., AlSi10Mg), rolling or welding, are hardly processable by L-PBF due to their susceptibility to solidification cracks (Al$\mathrm{Zn}-\mathrm{Mg}-\mathrm{Cu}$ (7XXX), Al-Cu-Mg (2XXX), Al-Mg-Si (6XXX)) and therefore need to be adapted or designed by other alloying additions (Ref 1). Such shortcomings triggered the development of new material concepts. Scalmalloy ${ }^{\circledR}$ is a $\operatorname{good}$ example, as it is one of the first high-strength aluminum alloys specifically developed for L-PBF (yield strength (YS) $\geq$ $520 \mathrm{MPa}$, fracture strain $(\mathrm{A})>10 \%$ after heat treatment) (Ref 2). Scalmalloy ${ }^{\circledR}$ contains magnesium and scandium as the main alloying elements, with the Sc content determining the maximum achievable strength of the alloy (Ref 3-7). On the other hand, $\mathrm{Mg}$ evaporates during the melting process which is known as "burn-off" (Ref 8-12). In addition, this evaporation leads to unstable material melting, melt pool dynamics that are difficult to control as there is a high amount of spatter caused by an interplay of the laser beam and the interaction with the material and its thermophysical properties such as specific heat capacity, thermal diffusivity, thermal conductivity, surface tension, and viscosity and the formation of welding fumes which mainly consist of $\mathrm{MgO}$. As a result, defects such as voids, layer bonding defects and process pores as well as inhomogeneous melting can occur, which also leads to an undesirable reduction in strength (Ref 11). High-strength and 
thermally resistant Al-Cr based alloy concepts newly developed by Airbus (Zicromal ${ }^{\circledR}$ - Al-Cr-Zr-Mn and Scancromal ${ }^{\circledR}$ - Al$\mathrm{Cr}-\mathrm{Sc}-\mathrm{Zr}$ (Ref 13)) are offering improved melting properties with significantly less welding fumes and spatter, as well as a melting process that is inherently robust and stable compared to Scalmalloy ${ }^{\circledR}$. To investigate this, in addition to high-speed recordings during the L-PBF process, surface tension measurements and evaporation analysis were carried out using electromagnetic levitation on the three different alloy concepts Zicromal ${ }^{\circledR}$, Scancromal ${ }^{\circledR}$, and Scalmalloy ${ }^{\circledR}$.

\section{Material and Methods}

\subsection{Powder}

The Zicromal® powder (Al-Cr4.8-Zr1.4-Mn1.4, wt.\%) was produced by Nanoval GmbH \& Co. KG. The powder production is a cold gas atomization process where the alloy is melted in a closed crucible. A gas stream feeds the molten metal into a convergent-divergent Laval nozzle, where it is accelerated to supersonic velocity. During the acceleration, the gas constantly transfers kinetic energy into the metal melt. After the narrowest cross section, the gas with the confined molten metal is accelerated to Mach number $>1$, followed by a spontaneously burst when the external gas pressure decreases. Due to surface tension, spherical droplets are formed, which cool down and solidify to form powder particles (Ref 14). The

Table 1 distribution of particle size $(\mu \mathrm{m})$

\begin{tabular}{lccc}
\hline alloys & $\boldsymbol{D}_{\mathbf{1 0}}$ & $\boldsymbol{D}_{\mathbf{5 0}}$ & $\boldsymbol{D}_{\mathbf{9 0}}$ \\
\hline Zicromal ${ }^{\circledR}$ & 18.7 & 29.8 & 53.1 \\
Scancromal ${ }^{\circledR}$ & 36.5 & 52.1 & 76.8 \\
Scalmalloy & 29.6 & 49.4 & 75.9 \\
\hline
\end{tabular}

Table 2 Chemical composition of the used Alloys in wt.\% (Powder)

\begin{tabular}{lcccccl}
\hline alloys & Al & Cr & Mg & Mn & Sc & Zr \\
\hline Zicromal ${ }^{\circledR}$ & Balance & 4.8 & $\ldots$ & 1.4 & $\ldots$ & 1.4 \\
Scancromal ${ }^{\circledR}$ & Balance & 2.6 & $\ldots$ & $\ldots$ & 0.72 & 0.25 \\
Scalmalloy & Balance & $\ldots$ & 3.18 & 0.39 & 0.73 & 0.3 \\
\hline
\end{tabular}

Scalmalloy® (Al-Mg3.18-Sc0.73-Mn0.39-Zr0.3, wt.\%) and the Scancromal ${ }^{\circledR}{ }^{\circledR}(\mathrm{Al}-\mathrm{Cr} 2.6-\mathrm{Sc} 0.72-\mathrm{Zr} 0.25$, wt.\%) powder were produced via inert gas atomization (IGA) by Toyo Aluminium K.K, Japan. The particle size distribution is shown in Table 1, and the chemical composition can be seen in Table 2. The chemical composition of the unprocessed powder material was determined by the manufacturer using inductively coupled plasma optical emission spectroscopy (ICP-OES) according to ASTM E3061 ICP. Figure 1 shows a single powder particle (recorded with SEM BSD) of Zicromal ${ }^{\circledR}$, Scancromal ${ }^{\circledR}$, and Scalmalloy®. Due to the high chromium content, many Cr-rich precipitates are visible on the Zicromal ${ }^{\circledR}$ particle, while only very few Cr-rich precipitates are visible on the Scancromal ${ }^{\circledR}$ particle. No precipitates were observed on the Scalmalloy® particle.

\subsection{Laser Powder Bed Fusion}

All the samples were printed with the laser powder bed fusion system SLM ${ }^{2} 125 \mathrm{HL}$ from SLM Solutions Group AG using a 3D-Scanoptic and an Ytterbium-YAG Fiber Laser which operates in $\mathrm{cw}$ (continuous wave) mode with a maximum laser power of $400 \mathrm{~W}$ (wavelength $1064 \mathrm{~nm}$ ). The Gaussian beam $\left(\mathrm{TEM}_{00}\right)$ focus diameter is about $85 \mu \mathrm{m}$. Argon was used as a protective gas in the build chamber. The build plate has the following dimensions: $125 \mathrm{~mm} \times 125 \mathrm{~mm}$ and is made out of Al-Mg4.5-Mn. All build-jobs were prepared using the software tool "Magics" from Materialise. For generating the parts, an alternating scan strategy (bi-directional line scan, also called "stripes") was used with a rotation of $67^{\circ}$ for each layer to avoid layer-wise fault propagation (see Fig. 2). The process parameters used to generate high-dense material quality can be taken from Table 3 .

\subsection{Microscopes, High-Speed Camera and Sample Preparation}

Scanning electron microscope (SEM) images of the powder particles were taken with Auriga 40 from Zeiss. The high-speed videos were recorded with a Photron FASTCAM SA-Z 2100k camera, Fig. 3, equipped with a far-field microscope $12 \mathrm{x}$ Navitar, using a frame rate (fps) of 3000 for process overview, a shutter speed of 1/3000-1/20000 s, and a resolution of $1024 \times 1024$ px. Additional illumination of the process was provided by two Vision Devices 7000 lumens, each equipped with several LED's, from the top and front window. The microstructure images were taken with the reflected-light microscope Polyvar Sc from Leica after the sample had been etched according to Barker (Ref 15). The samples were

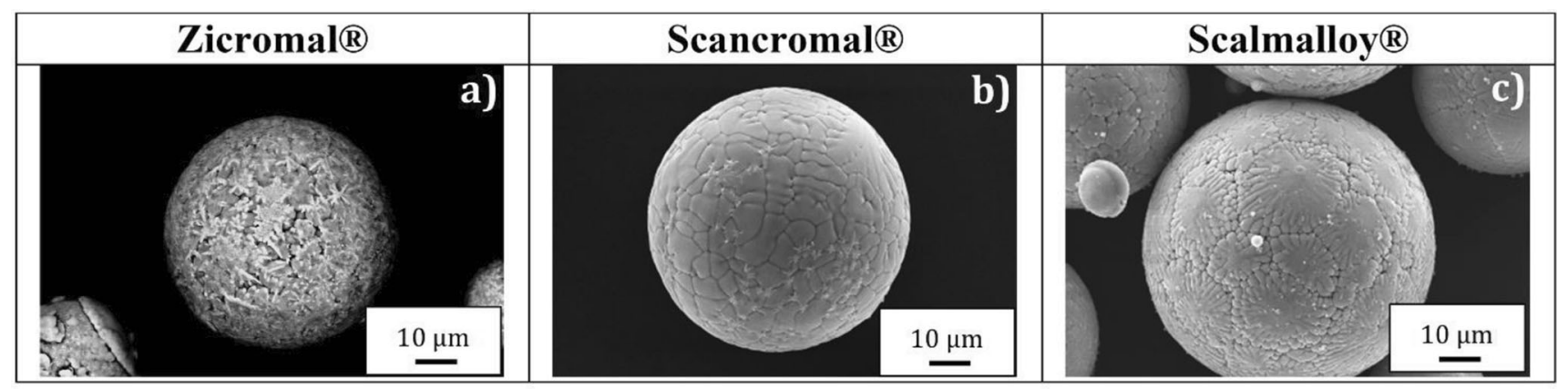

Fig. 1 SEM (BSD) pictures of (a) Zicromal ${ }^{\circledR}$, (b) Scancromal ${ }^{\circledR}$ and (c) Scalmalloy ${ }^{\circledR}$ powder 
embedded (cold) with epoxy resin, grinded and polished accordingly. For Barker-etching, the samples were prepared via electrolytic polishing (voltage: $30 \mathrm{~V}$, duration: $60 \mathrm{~s}$ ).

\subsection{Electromagnetic Levitation}

The surface tension measurements of three liquid aluminum alloys were performed by employing the oscillating droplet method using the electromagnetic levitation (EML) facility. Details of the device and the measurement procedure are described in Ref 16, 17. The facility includes a pair of levitation coils of opposite polarity. The axes of both coils are aligned parallel to the direction of the gravitational force. The spacing between the coils is less than $10 \mathrm{~mm}$. They are operated with an alternating current of $200 \mathrm{~A}$ at $250 \mathrm{kHz}$. This leads to a stable positioning of the initially spherical sample $\left(R_{0} \approx\right.$ $3.2 \mathrm{~mm}, M \approx 0.32 \mathrm{~g}$ ) in their center. At the same time, the sample is heated and melted by eddy currents induced inside. The experiments are performed under a protective atmosphere of $\mathrm{He}(99.9999 \%$ purity) maintained at 750 mbar. The temperature was measured with a single-color IR-pyrometer and controlled by adjusting a laminar gas flow of the processing atmosphere admitted to the sample via a small nozzle.

A high-speed camera is installed on top of the observation window of the chamber in order to record the projection area of the levitated droplet with a frame rate of $800 \mathrm{~Hz}$. The frequency spectrum of the radius change was analyzed using the fast Fourier transform (FFT).

The surface tension measured at different temperatures can be calculated using Rayleigh's equation (Ref 18) with Cummings and Blackburn's correction (Ref 19):

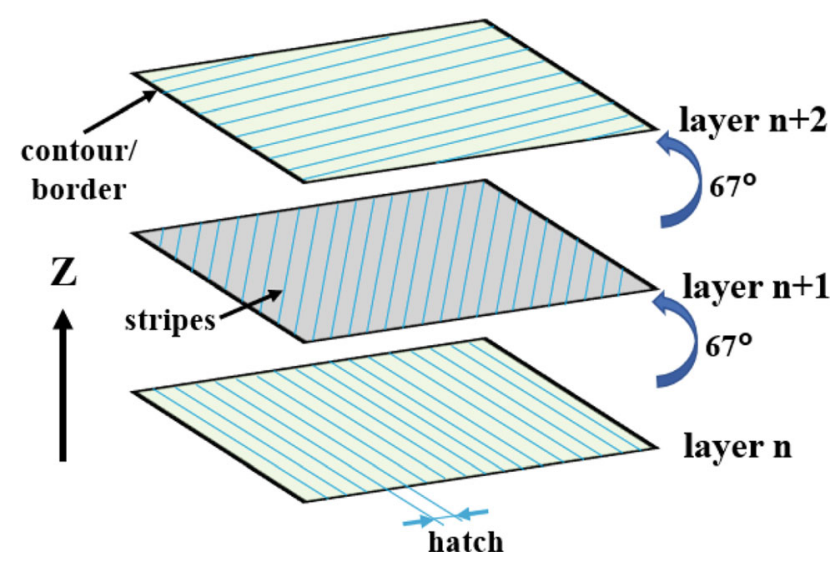

Fig. 2 Schematic representation of the scan strategy "stripes" with hatch distance, contour/border, rotation of $67^{\circ}$ for each layer and build direction $\mathrm{Z}$

$$
\sigma=\frac{3 M}{32 \pi}\left(\sum_{m=0, \pm 1, \pm 2} \frac{1}{5} \omega_{l=2, m}^{2}-1.9 \omega_{t r}^{2}-0.3 \omega_{\mathrm{tr}}^{-2}\left(\frac{g}{R_{0}}\right)^{2}\right)
$$

In Equation 1, $\sigma$ is the surface tension, $M$ denotes the sample mass, $R_{0}$ is the initial sample radius, $g$ is the gravitational constant, and $\omega_{l=2, m}$ denotes the fundamental frequency of the second oscillation mode and $m=0, \pm 1, \pm 2$ is the corresponding sub-mode. In Eq (1), the translational frequency is denoted by $\omega_{\mathrm{tr}}$.

For the experiments for surface tension measurements, the samples were superheated above the liquidus temperature $T_{\mathrm{L}} \approx 1080 \mathrm{~K}$ to a maximum temperature of about $1620 \mathrm{~K}\left(T_{\mathrm{L}}+\right.$ $540 \mathrm{~K})$; an additional preliminary EML experiment was performed using Zicromal ${ }^{\circledR}$ with a maximum superheat to about $2060 \mathrm{~K}\left(T_{\mathrm{L}}+970 \mathrm{~K}\right)$, and by comparing the sample mass before and after the EML processing, the impact of evaporation on the sample mass loss during the experiments can be evaluated at different superheating levels.

\section{Results}

\subsection{Optimum Process Parameters}

In order to produce the highest possible densities ( $>99.9 \%$ ) of the material, a detailed parameter study is required. Especially in the aerospace industry, a corresponding material quality is of utmost importance, particularly with regard to the fatigue properties. For this purpose, 25 density cubes (for each material) were printed with the SLM®125HL. Each cube $(10 \times 10 \times 10 \mathrm{~mm})$ is generated with different parameters. On the one hand (using the example of Zicromal ${ }^{\circledR}$ ), the hatch distance was varied (0.11-0.15 mm, $0.1 \mathrm{~mm}$ increments), and on the other hand, the scanspeed was varied $(1200-1600 \mathrm{~mm} / \mathrm{s}, 100$ $\mathrm{mm} / \mathrm{s}$ increments). The laser power of $350 \mathrm{~W}$ remains constant (using the example of Zicromal ${ }^{\circledR}$ ). For Scancromal $\AA$, the parameters for the scanspeed were varied between 800 and $1300 \mathrm{~mm} / \mathrm{s}$ and the hatch distance was between 0.08 and 0.12 $\mathrm{mm}$ (at constant laser power of $355 \mathrm{~W}$ ). For Scalmalloy ${ }^{\circledR}$, the scanspeed was varied between 600 and $1000 \mathrm{~mm} / \mathrm{s}$ and the hatch distance was between 0.08 and 0.12 (at constant laser power of $370 \mathrm{~W}$ ). The layer thickness is $30 \mu \mathrm{m}$ and argon was used as the process/protective gas. The cubes were printed with the exposure strategy "stripes". Subsequently, the cross section (Z-plane) of each individual cube is evaluated under the reflected-light microscope with regard to density or porosity. Pores, voids, and inclusions appear black in the reflected-light microscope, while the solidified material appears gray. The black area (sum of pores, voids, and inclusions, percentage) is

Table 3 Process parameter for generating high-dense material quality

\begin{tabular}{|c|c|c|c|c|c|c|}
\hline alloys & $\begin{array}{c}\text { power } P_{L}(W) \\
\text { volume }\end{array}$ & $\begin{array}{l}\text { scanspeed versus } \\
(\mathrm{mm} / \mathrm{s}) \text { volume }\end{array}$ & $\begin{array}{c}\text { hatch d }(\mathrm{mm}) \\
\text { volume }\end{array}$ & $\begin{array}{l}\text { layer thickness } \\
\qquad t_{L}(\mu \mathrm{m})\end{array}$ & $\begin{array}{l}\text { power } P_{L, b}(W) \\
\text { contour/border }\end{array}$ & $\begin{array}{c}\text { Scanspeed versus } b(\mathrm{~mm} / \mathrm{s}) \\
\text { contour/border }\end{array}$ \\
\hline Zicromal® & 350 & 1500 & 0.1 & 30 & 375 & 800 \\
\hline Scancromal® & 355 & 1100 & 0.1 & 30 & 300 & 800 \\
\hline Scalmalloy® & 370 & 800 & 0.1 & 30 & 370 & 1200 \\
\hline
\end{tabular}


subtracted from the gray area (high-dense printed material, percentage). The result can be seen in Fig. 4. The 25 black points of the heat map show the determined porosity of each printed cube. The values in between were interpolated. The cube A4 (hatch $0.11 \mathrm{~mm}$, scanspeed $1500 \mathrm{~mm} / \mathrm{s}$, power $350 \mathrm{~W}$ ) was accordingly printed best with a density of $99.9 \%$. The parameter study explained was carried out with all three aluminum alloys (using different parameters). However, the example described here refers to Zicromal ${ }^{\circledR}$ (Fig. 4b).

The developed process parameters of the different aluminum alloys used in this work lead to material densities of $>99.9 \%$. Due to the process unsteadiness (high melt dynamics), powder

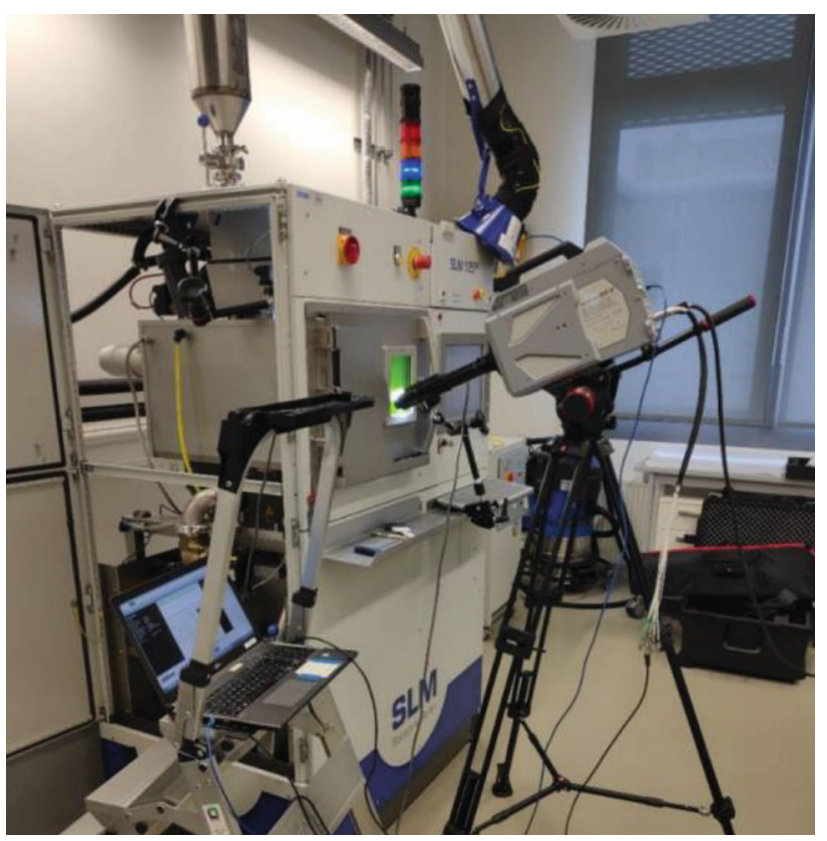

Fig. 3 SLM ${ }^{\circledR} 125 \mathrm{HL}$ and high-speed camera setup

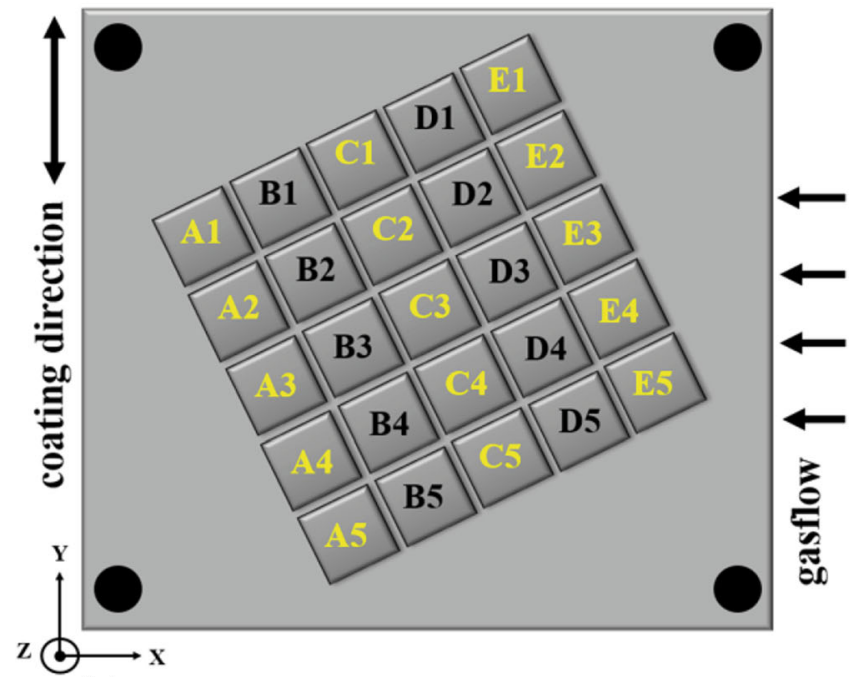

(a) particles melted and swirled around by the laser can be deposited on an already solidified layer. These particles can then lead to inclusions and layer bonding defects, as these particles are partially not removed by the re-coater (Fig. 5, schematic example of Scalmalloy®). In principle, such defects are independent of the material. But the more unstable (more spatter) a process is, the more likely it is that such inclusions will occur. The power density is no longer sufficient to completely melt the new powder layer, including the adherent (usually also agglomerated) powder particle. Such defects lead to a drastic reduction in fatigue properties, as such defects can act as crack initiation sites.

\subsection{L-PBF Process}

Figure 6(a), (b) and (c) shows a single powder layer of each alloy concept as the laser scans over the powder bed, melting the powder and thus successively generating the component. The brightly glowing plasma plume appears very large and pronounced in all three images (Fig. 6a, b and c). This can be explained by the somewhat longer exposure time of the reflex camera and by the bi-directional exposure of the laser. The advantage of this exposure time is that one can see the spatter trajectories (ejected/flung out of the melt pool) and the powder particles whirled up and partly melted by the laser, flying around and partly agglomerating. The direction of these spatter and powder particles are mainly from right to left, i.e., in the direction of the protective gas flow (white arrow). Occasionally, it can be seen that spatters and particles are also thrown to the right. However, these are quickly transported back to the left, i.e., in the opposite direction, by the cross-jet. Since the exposure sequence is contrary to the gas flow, some powder particles that have melted land on a surface already exposed and adhere to it. This can result in a lack of fusion, as these particles cannot be removed by the re-coater when applying a new powder layer.

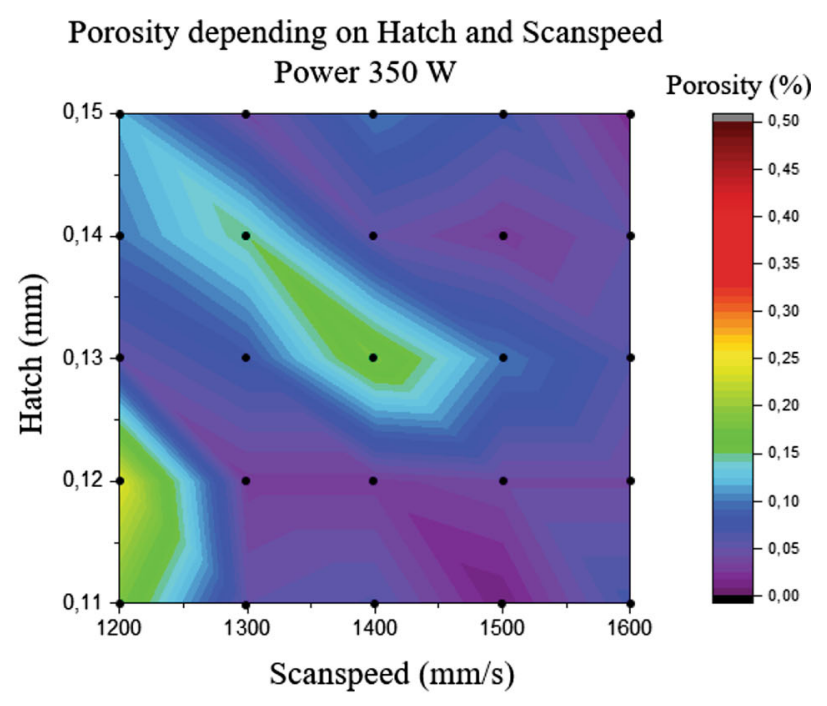

(b)

Fig. 4 Process parameters (a) 25 density cubes on build plate of SLM ${ }^{\circledR} 125$ (schematically) for process parameter study/optimization, (b) heat map showing the different results (porosity) of the 25 printed cubes (on the example of Zicromal®), each black dot in the heat map shows the measured (analyzed with reflected-light microscope) porosity, $\mathrm{Z}$ shows the build direction 
Looking at the melted and solidified surfaces of all alloy concepts in Fig. 6, it can be seen that they differ significantly. A look at the powder bed next to the generated material also shows clear differences due to the respective alloy concept and the resulting process dynamics and chemical reactions. The generated surfaces of Zicromal® (Al-Cr-Zr-Mn) in Fig. 6a are metallic shiny and look like stainless steel. Occasionally, adherent powder particles or solidified weld spatter can also be seen on the surface. Some dust is visible on the left side of a melted cylinder in Fig. 6(a). This could be explained by the "burn-off" of manganese during the process, which reacts with the residual oxygen present in the construction chamber (approx. 300-1000 ppm) and is then deposited on the powder bed to the left of the generated surfaces (due to the gas flow). In the case of Scancromal ${ }^{\circledR}$ (Al-Cr-Sc-Zr) in Fig. 6(b), the generated surfaces look shiny metallic, and the laser light or the plasma plume is reflected in the surface. The surface also appears very smooth. Occasionally, powder particles or weld spatter can be seen on the already exposed/generated surface in the case of Zicromal ${ }^{\circledR}$ and Scancromal ${ }^{\circledR}$. In Figure $6(\mathrm{c})$, the laser scans straight across the powder bed consisting of Scalmalloy® (Al-Mg-Sc-Mn-Zr). The resulting deep black surface of the already generated material can be seen particularly clearly, caused by the black dust deposited on and to the

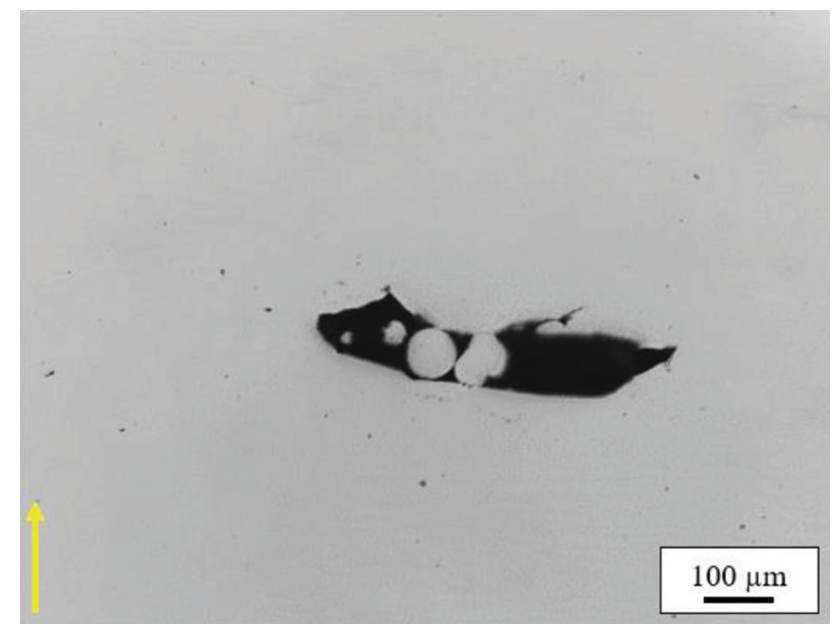

Fig. 5 Schematic layer bonding defect caused by non-melted (or partially melted) particles that have fallen and adhered to the already solidified layer due to unsteady melting dynamics, material: Scalmalloy ${ }^{\circledR}$, yellow arrow shows the build direction $\mathrm{Z}$ left of the component due to the gas flow. The dust is most likely magnesium oxide $(\mathrm{MgO})$, which is formed during the process by the "burn-off" the low-melting and low-boiling point element magnesium. Magnesium has the lowest evaporation point and the highest vapor pressure (Ref 12, 20) compared to all other alloying elements in Scalmalloy®. In the upper part of Fig. 6(c), unevenness can be seen shining through the powder deposited by the re-coater. This can cause layer bonding errors/lack of fusion. The question now arises as to which chemical and/or physical processes are responsible for these significant differences in the melting behavior. In order to be able to assess the three different alloy concepts with regard to their melting and remelting behavior, the macroscopic images taken with a reflex camera are not sufficient. Therefore, microscopic videos/images were taken with a high-speed camera (see Fig. 7).

In order to understand the melt dynamics, Fig. 7 shows an image sequence recorded with a high-speed camera during the L-PBF process with the alloy concepts Zicromal ${ }^{\circledR}$ (a-c), Scancromal ${ }^{\circledR}(\mathrm{d}-\mathrm{f})$, and Scalmalloy ${ }^{\circledR}$ (g-i) at the beginning of the melting process $(\mathrm{a}, \mathrm{d}, \mathrm{g}$ ), after three-quarters of the generated surface $(b, e, h)$ and during the contour-scan (border) at the end of the melting process. In the case of Zicromal ${ }^{\circledR}$ in Fig. 7(a), (b) and (c), a pronounced plasma plume can be seen, as well as numerous weld spatters and melted powder particles flying around (brightly shining). This could also be related to the higher scanning speed of $1500 \mathrm{~mm} / \mathrm{s}$ (compared to the other two alloy concepts). Especially during the contour-scan (Fig. 7c), many spatters and powder particles are ejected from the melt pool and powder bed, whereby the scanning speed for the contour-scan is only $800 \mathrm{~mm} / \mathrm{s}$. Some of the brightly glowing droplets land directly on the already exposed surface and weld/fuse with it. Other molten powder particles roll over the powder bed and agglomerate with other particles to form an even larger one. Another observation during the process is that flying particles/droplets or weld spatter are hit again by the laser beam and thus accelerated further. Due to the reflection of the plasma plume on the component surface, the individual and small weld seams can also be seen in the video, which is even, smooth, and perfectly scaled. This is not easily recognizable in Fig. 7 due to the poor screenshot quality. If we now compare Zicromal ${ }^{\circledR}$ (Al-Cr-Zr-Mn) from Fig. 7(a), (b) and (c) with Scancromal ${ }^{\circledR}$ (Al-Cr-Sc-Zr) from Fig. 7(d), (e) and (f), it becomes clear that this new alloy concept (Ref 13) recently developed by Airbus can be melted and remelted much more robustly. This is evident not only from a much less pronounced

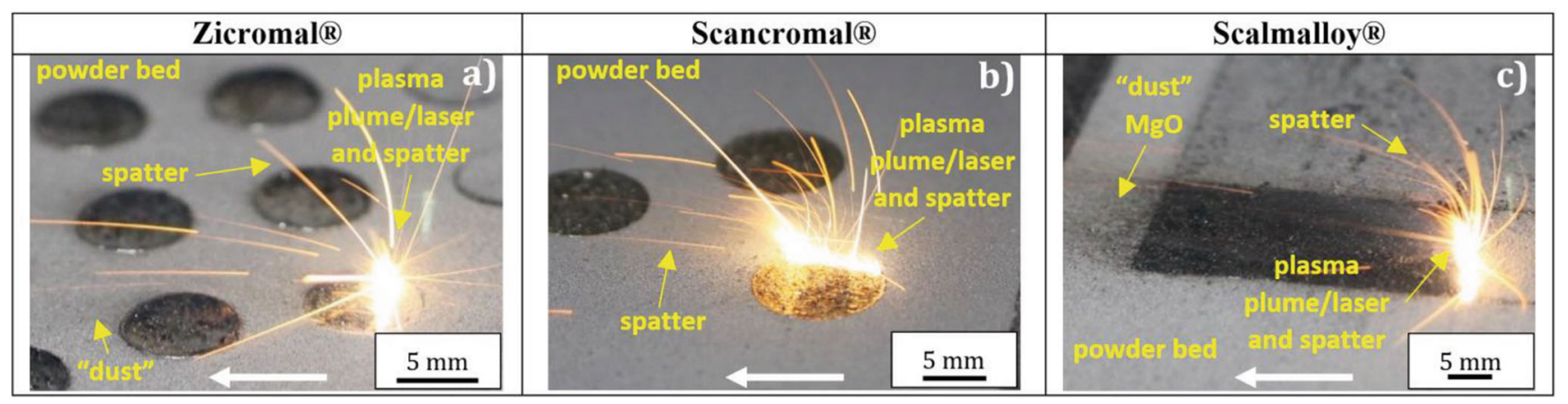

Fig. 6 Process behavior during L-PBF recorded with a reflex camera, (a) Zicromal ${ }^{\circ}$, (b) Scancromal ${ }^{\circledR}$, (c) Scalmalloy ${ }^{\circledR}$, argon gas flow from right to left (white arrow) 


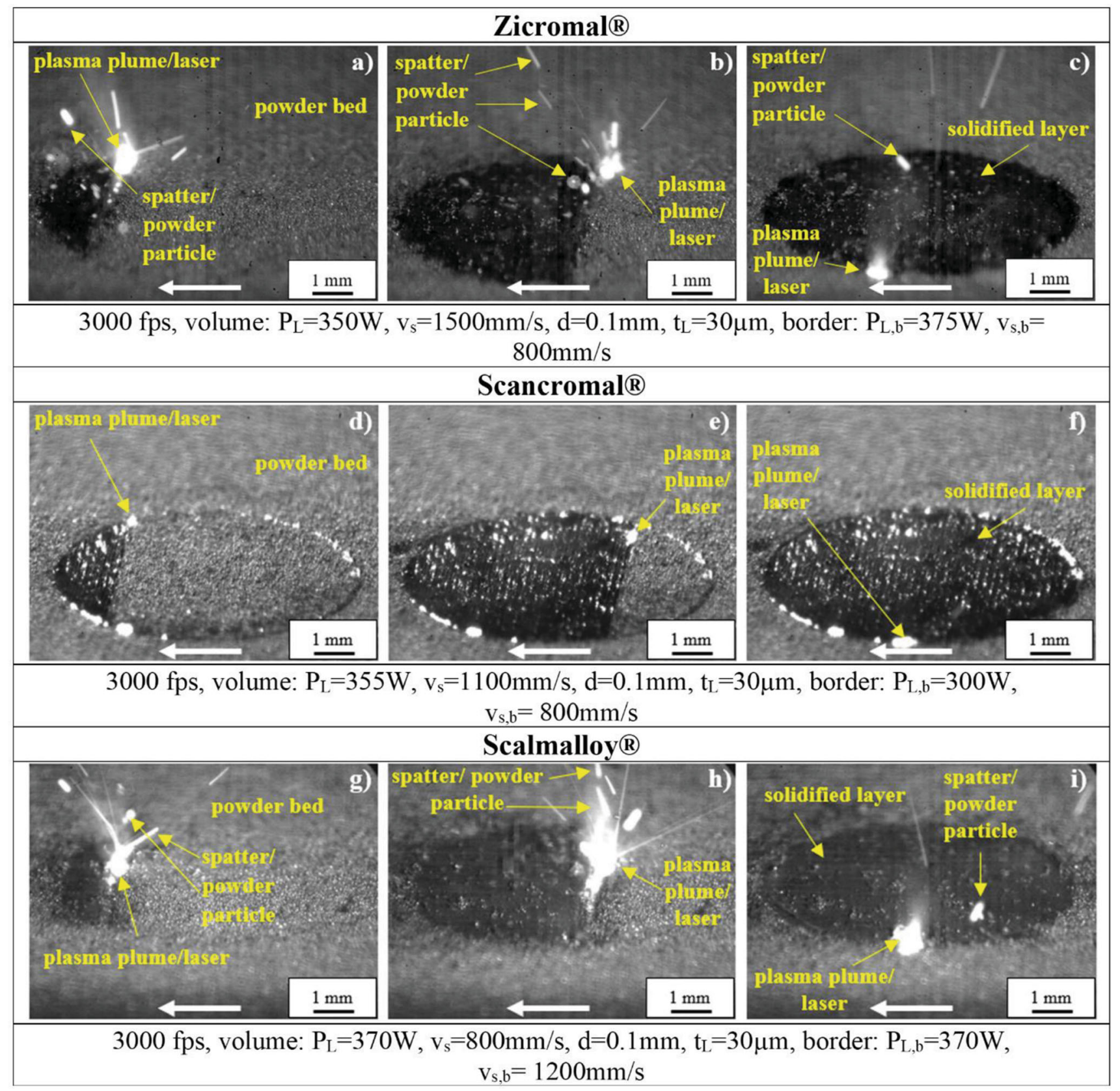

Fig. 7 Process parameter and melt puddle dynamics/spatter formation during L-PBF process, screenshots taken from high-speed-videos, (a-c) Zicromal ${ }^{\circledR}$, (d-f) Scancromal ${ }^{\circledR},\left(\right.$ g-i) Scalmalloy ${ }^{\circledR}$, argon gas flow from right to left (white arrow)

plasma plume but also from the reduced amount of weld spatter and particles whirled up and flying around. The scanning speed for the volume range with Scancromal ${ }^{\circledR}$ is somewhat lower than with Zicromal ${ }^{\circledR}$ at $1100 \mathrm{~mm} / \mathrm{s}$, but this should only play a minor role with regard to spatter formation. Although the speed of the laser is the same for the contour-scan (border) at $800 \mathrm{~mm} / \mathrm{s}$, the number of spatters and particles is significantly lower with Scancromal ${ }^{\circledR}$ than with Zicromal ${ }^{\circledR}$. In the case of Scalmalloy ${ }^{\circledR}$ in Fig. $7 \mathrm{~g}, \mathrm{~h}$ and $\mathrm{i}$, there is a similarly high process unsteadiness as in the case of Zicromal ${ }^{\circledR}$, although the scanning speed for contour-scan is $1200 \mathrm{~mm} / \mathrm{s}$ for Scalmalloy ${ }^{\circledR}$ and the speed of the laser for the volume range is only $800 \mathrm{~mm} /$ s. The question that now arises is why the two alloy concepts Zicromal ${ }^{\circledR}$ (Al-Cr-Zr-Mn) and Scalmalloy ${ }^{\circledR}$ (Al-Mg-Sc-Mn-
$\mathrm{Zr}$ ), differ so significantly in their melt dynamics compared to Scancromal ${ }^{\circledR}(\mathrm{Al}-\mathrm{Cr}-\mathrm{Sc}-\mathrm{Zr})$.

The process of L-PBF is highly complex, and numerous factors (e.g., viscosity, surface tension, etc.) can influence the process imbalances (spatter formation, swirled powder particles, etc.). The correlation between spatter formation and thermophysical properties is also described in the literature (Ref 21-25). The Weber number $(\mathrm{We})$ is a metric to compare the inertia to the surface tension of the fluids,

$W e=\frac{\rho v^{2} l}{\sigma}$

where $\rho$ and $\sigma$ are the density and surface tension of the molten alloy, $v$ and $l$ are the velocity and characteristic length of the 
melts. When the Weber number $W e$ increases over a critical point, the inertia of the melts will overcome the surface tension, and droplets will escape the weld pool to form spatters. As described in $\mathrm{Eq} \mathrm{2,} \mathrm{the} \mathrm{Weber} \mathrm{number} \mathrm{We}$ is inversely proportional to the surface tension $\sigma$, indicating that the melts with relatively lower surface tension are theoretically prone to form spatter, and the melts with higher surface tension will be more robust during the melting process. The melt flow velocity $v$ also depends on the density and viscosity, indicating more influencing factors. In this work, we focused on the investigation of the surface tension as one of the potentially dominating terms. In more detail, the surface tensions of all three alloy concepts were measured and investigated using electromagnetic levitation.

\subsection{Microstructure Analysis}

An overview image (Fig. 8) is shown to illustrate the different planes in the microstructure. Figure 9 shows the microstructure of the different aluminum alloys studied in the Z-plane (build direction). Figure 10 shows the cross section (SEM/BSD, XY-plane) of Zicromal ${ }^{\circledR}$. In order to gain a better understanding of the grain growth and possible precipitates, the polished sections were firstly etched with Barker and viewed under the reflected-light microscope in polarized light (Fig. 9a, $\mathrm{b}$ and c) and secondly, the polished areas were analyzed in the SEM with the BSD detector (Fig. 9d, e and f). Zicromal ${ }^{\circledR}$ (Fig. $9 \mathrm{a}+\mathrm{d}$ ) was found to have a similar bimodal microstructure to Scalmalloy ${ }^{\circledR}$ (Fig. 9c+f). This bimodal microstructure consists of a coarse grain region (columnar grains $=\mathrm{CG}$ ) and a fine-grain region (equiaxed grains $=\mathrm{EG}$ ). The columnar grains solidify in the melt pool center in a direction from outside to inside (or from the bottom to the top) due to the high thermal gradients.

The fine-grain area formed during solidification prevents/ blocks/inhibits the grain growth of the columnar grains of the underlying weld beads in the build direction. In Zicromal ${ }^{\circledR}$, the primary $\mathrm{Al}_{3} \mathrm{Zr}$ precipitates act as heterogeneous nuclei in the melt for the EG area. Chromium or Al-Cr phases $\left(\mathrm{Al}_{13} \mathrm{Cr}_{2}\right.$ and $\mathrm{Al}_{12}(\mathrm{Cr}, \mathrm{Mn})$, size approx. 1-2 $\left.\mu \mathrm{m}\right)$ seem not to influence the precipitation of the $\mathrm{Al}_{3} \mathrm{Zr}$ phases (size approx. $200 \mathrm{~nm}$ ) and thus the formation of the $\mathrm{FG}$ area. The $\mathrm{Al}_{13} \mathrm{Cr}_{2}$ phase has a monoclinic, $\mathrm{C} 2 / \mathrm{m}$ crystalline structure and is noncoherent with the matrix (Ref 26). Therefore, they do not act as potent nuclei. In Scalmalloy®, primary (semi-) coherent $\mathrm{Ll}_{2} \mathrm{Al}_{3} \mathrm{Sc}$ or $\mathrm{Al}_{3}\left(\mathrm{Sc}_{\mathrm{x}}, \mathrm{Zr}_{1-\mathrm{x}}\right)$ phases (size approx. 2-5 nm) act as nuclei for the EG region. However, Scancromal ${ }^{\circledR}$ shows a different microstructure, although, as with Scalmalloy ${ }^{\circledR}$, it also contains scandium as a grain-refining and strength-increasing element. Figure $9(b)+(e)$ shows (on the example of Scancromal®) a

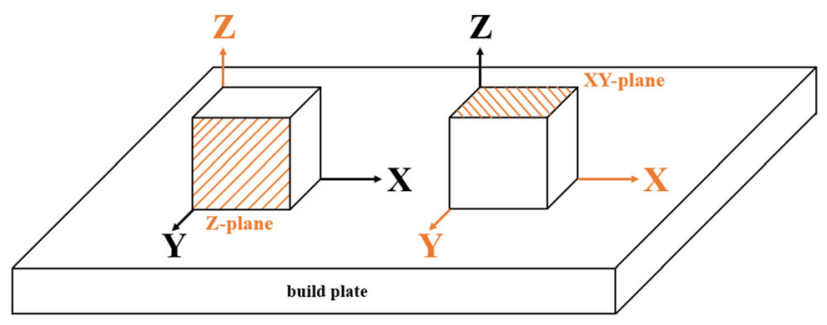

Fig. 8 Overview of the different planes $Z$ and $X Y$ for cross sections clear epitaxial grain growth across several weld beads. The grain-refining effect known for scandium did not occur. Primary $\mathrm{Al}_{13} \mathrm{Cr}_{2}$ phases are visible above the weld pool boundary (yellow dotted line) in the form of a seam. With Zicromal®, an enrichment of the $\mathrm{Al}_{13} \mathrm{Cr}_{2}$ phase with $\mathrm{Zr}$ could not be observed. However, there seems to be an interaction between the $\mathrm{Al}_{13} \mathrm{Cr}_{2}$ phase and manganese. EDX investigations have shown that the Al-Cr phases are enriched with manganese (possibly $\mathrm{Al}_{12}(\mathrm{Cr}, \mathrm{Mn})$ ). Further information on the microstructure formation of Scancromal ${ }^{\circledR}$ and Scalmalloy ${ }^{\circledR}$ can be taken from (Ref 27).

Due to the high density of primary Al-Cr-Mn precipitates in the EG area (see Fig. 9d), it is not easy to recognize the finegrain area in Zicromal ${ }^{\circledR}$. Therefore, the XY-plane was examined in the SEM with BSD detector (see Fig. 10). The size difference of the columnar grains (CG) and the equiaxed grains (EG) can be seen very clearly. In the EG area, numerous primary Al-Cr-Mn dispersoids are again visible. The white dots in the columnar grains (CG) also show smaller Al-Cr precipitates that are homogeneously distributed.

\subsection{Surface Tension Results}

The surface tensions of three aluminum alloys are presented in Fig. 11 with a linear fit as a function of temperature $T$. The temperature range is about $1050 \mathrm{~K}$ to $1580 \mathrm{~K}$; the measurements of each alloy are represented by different symbols in Fig. 11, and each data point denotes the value obtained at a specific temperature. Within the temperature range from $1050 \mathrm{~K}$ (near $T_{\mathrm{L}}$ ) to $1580 \mathrm{~K}$ (about $T_{\mathrm{L}}+500$ ), the surface tensions of Zicromal ${ }^{\circledR}$, Scancromal ${ }^{\circledR}$, and Scalmalloy ${ }^{\circledR}$ are in the range of $0.858 \pm 0.005 \sim 0.955 \pm 0.021 \mathrm{~N} \mathrm{~m}^{-1}, 0.811 \pm$ $0.015 \sim 0.998 \pm 0.015 \mathrm{~N} \cdot \mathrm{m}^{-1}$, and $0.789 \pm 0.032 \sim 0.993 \pm$ $0.025 \mathrm{~N} \cdot \mathrm{m}^{-1}$, respectively (compared to pure aluminum: 0.871 $\mathrm{N} \cdot \mathrm{m}^{-1}$ to Ref 28,2 and $0.868 \mathrm{~N} \cdot \mathrm{m}^{-1}$ to Ref 29). The relative uncertainty of the surface tension, measured by this procedure, is estimated as $\Delta \sigma / \sigma \approx 1-5 \%$. The results are then fitted using Eq (3), and the fitting coefficients are displayed in Table 4, where $\sigma_{\mathrm{L}}$ denotes the surface tension at the liquidus temperature $T_{\mathrm{L}}$ and $\mathrm{d} \sigma / \mathrm{dT}$ is the slope representing the changes of surface tension to the temperature.

$\sigma=\sigma_{L}+\frac{\mathrm{d} \sigma}{\mathrm{dT}}\left(T-T_{L}\right)$

The fitting results showed that the Al-Mg based alloy Scalmalloy ${ }^{\circledR}$ presents a lower surface tension than the Al-Cr based alloys Zicromal ${ }^{\circledR}$ and Scancromal ${ }^{\circledR}$. The difference is less than $4 \%$ near their liquidus temperature $T_{\mathrm{L}} \approx 1080 \mathrm{~K}$. As the temperature increases from about $T_{\mathrm{L}}+100 \approx 1180 \mathrm{~K}$ to $T_{\mathrm{L}}$ $+500 \approx 1580 \mathrm{~K}$, Scalmalloy ${ }^{\circledR}$ exhibits lower values than the others with a difference of about $3 \%$ to $8 \%$. It should be noticed that the upper bound of the uncertainty is about $5 \%$ near $T_{\mathrm{L}}$, and the significance of surface tension difference needs to be discussed in the scope of the next section.

\subsection{Evaporation Analysis}

During the superheating and cooling stages of the molten alloys processed in EML, the evaporation may influence the thermophysical properties and composition changes. In previous investigations, Langmuir's theory (Ref 30) was used to evaluate the evaporation of a molten metal droplet using electrostatic levitation (Ref 31 ) and electromagnetic levitation 

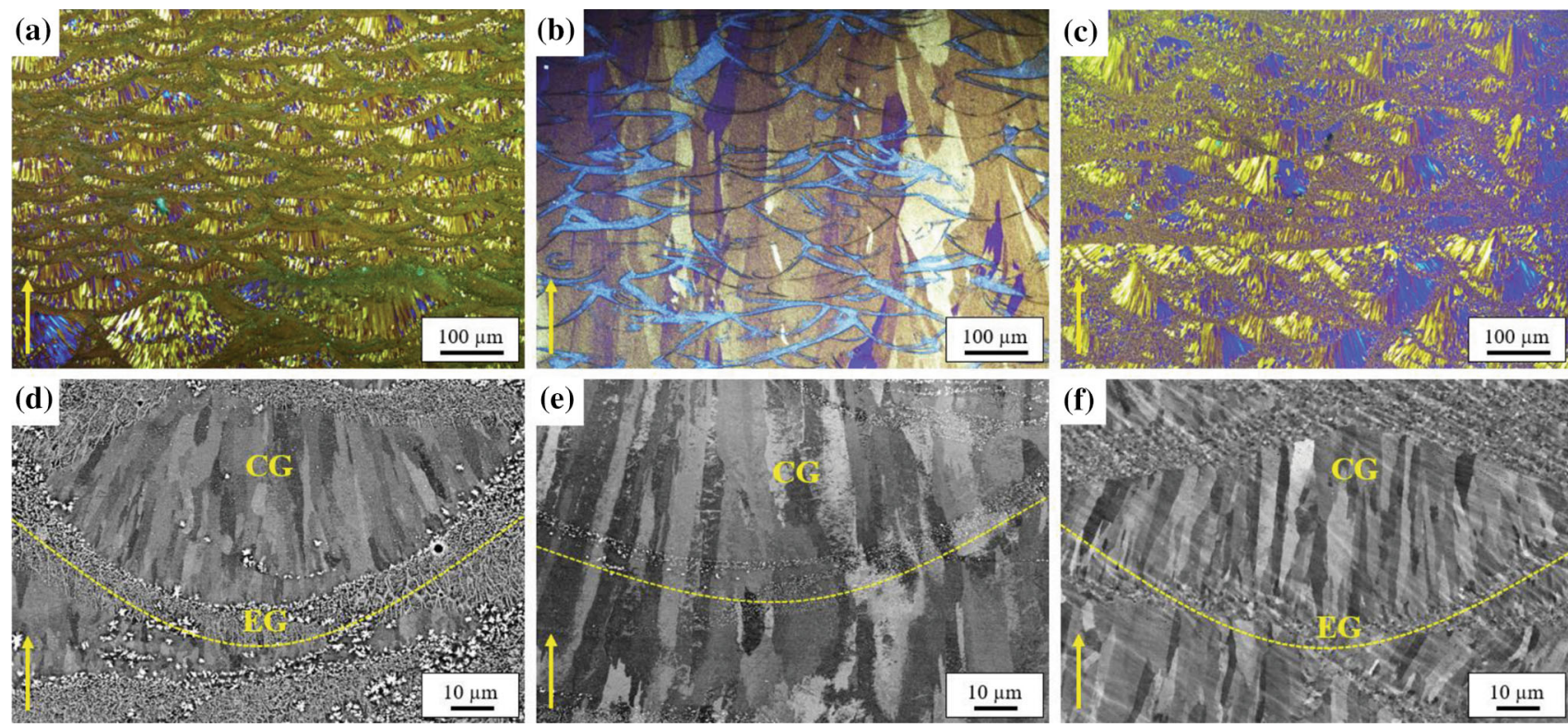

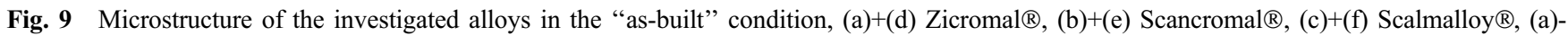
(c) optical micrographs (of cross sections) etched with Barker's Reagent (polarized light), (d)-(f) SEM/BSD pictures (of cross sections) of single welding beads, yellow dotted line shows weld seam border, yellow arrow shows the build direction Z (Color figure online)

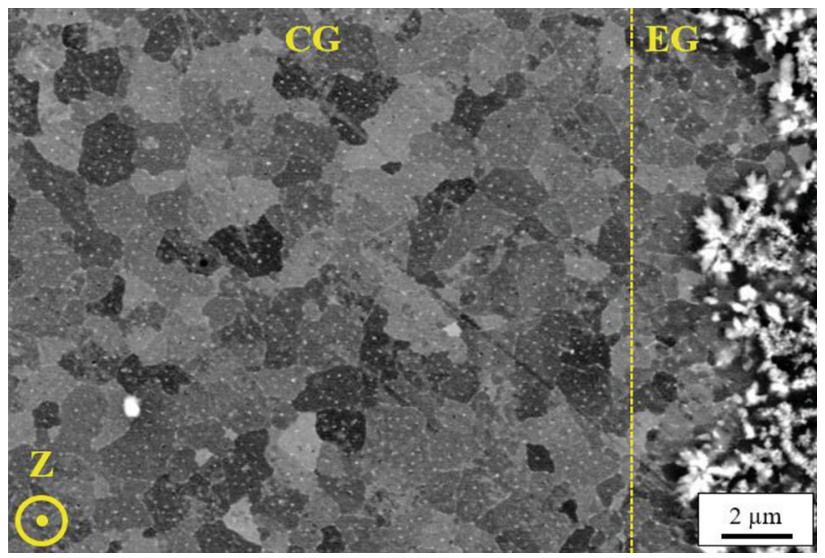

Fig. 10 SEM/BSD pictures (XY-plane, cross section) of Zicromal ${ }^{\circledR}$ in the "as-built" condition, yellow dotted line shows transition area from CG to EG, yellow arrow shows the build direction $\mathrm{Z}$ (Color figure online)

in microgravity (Ref 32,33). For an individual substance $i$ in the liquid mixture, its evaporation rate $\mathrm{dm}_{i} / \mathrm{dt}\left(\mathrm{kg} \cdot \mathrm{s}^{-1}\right)$ can be predicted using Langmuir's equation,

$\frac{1}{M_{i}} \frac{\mathrm{dm}_{i}}{\mathrm{dt}}=\frac{\left(a_{i} P_{v, i}-P_{\text {ref }}\right) \alpha_{i} A_{s}}{\sqrt{2 \pi M_{i} R_{G} T}}$

where $a_{i}$ is the activity, $A_{s}$ is the surface area of the liquids, $M_{i}$ is the molar mass, $R_{G}$ is the gas constant, $T$ is the temperature, $P_{v, i}$ is the vapor pressure, $P_{\text {ref }}$ is the reference pressure that can be set to zero, and $\alpha_{i}$ is the shielding factor that presents a correction reducing the evaporation in an inert gas atmosphere compared to in a vacuum. Specifically, $a_{i}=\gamma_{i} c_{i}$ for activity coefficient $\gamma_{i}$ and concentration $c_{i}$ for an ideal mixture of liquid, $a_{i}=c_{i}$ such that $\gamma_{i}=1$. Due to the lack of knowledge of the activity of the selected alloys, an ideal solution is assumed. For the actual case, $\gamma_{i}$ can be either larger or smaller than 1 for

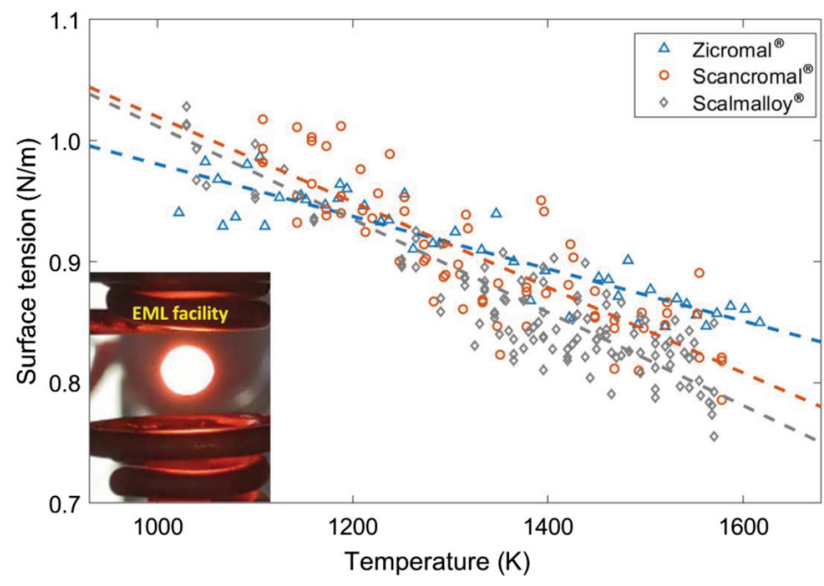

Fig. 11 Surface tensions of $\mathrm{Al}-\mathrm{Cr}$ and $\mathrm{Al}-\mathrm{Mg}$ based alloys measured using EML

\section{Table 4 Coefficients for surface tension linear fit}

\begin{tabular}{|c|c|c|c|}
\hline alloys & $T_{\mathrm{L}}(\mathrm{K})$ & $\sigma_{L}\left(\mathrm{~N} \mathrm{~m}^{-1}\right)$ & $d \sigma / \mathrm{dT}\left(\mathrm{N} \mathrm{m}^{-1} \cdot \mathrm{K}^{-1}\right)$ \\
\hline Zicromal® & 1087 & $0.962 \pm 0.048$ & $(-2.16 \pm 0.31) \times 10^{-4}$ \\
\hline Scancromal ${ }^{\circledR}$ & 1058 & $0.999 \pm 0.050$ & $(-3.53 \pm 0.56) \times 10^{-4}$ \\
\hline Scalmalloy® & 1080 & $0.981 \pm 0.049$ & $(-3.85 \pm 0.40) \times 10^{-4}$ \\
\hline
\end{tabular}

different elements in a composition, and the uncertainty will arise using the ideal solution assuming $\gamma_{i}=1$ for all elements. Therefore, the mass loss of each element in the molten alloy can be estimated by integrating Eq (4) over time $t$.

The vapor pressure of individual element $P_{v, i}$ can be estimated using Alcock's four-term equation and fitting coefficients of $A, B, C$ and $D(\operatorname{Ref} 34)$, 
$\log P_{v, i}(\mathrm{~atm})=A+B \cdot T^{-1}+C \cdot \log T+D \cdot T \cdot 10^{-3}$

The shielding factor $\alpha$ can be calculated using Fromm's equation (Ref 35),

$\alpha=\frac{1}{1+K P_{G}^{n}}$

where $P_{G}$ is the pressure of inert gas atmosphere, $K$ and $n$ are constants that are recommended to be $K=0.012$ and $n=1.0$ for metallic elements in an argon atmosphere; for $P_{G}=750 \mathrm{mbar}, \alpha$ $\approx 1.11 \times 10^{-3}$. In a helium atmosphere, the shielding effects are weaker than argon such that it exhibits a faster evaporation rate by a factor of

$K_{\mathrm{He} / \mathrm{Ar}}=\frac{\sqrt{1+M_{i} / M_{\mathrm{He}}}}{\sqrt{1+M_{i} / M_{\mathrm{Ar}}}}$

where $K_{\mathrm{He} / \mathrm{Ar}}>2$ for $M_{i}>20 \times 10^{-3}\left(\mathrm{~kg} \mathrm{~mol}^{-1}\right)$. The modified shielding factor for individual element $i$ in a helium atmosphere becomes

$\alpha_{i}=\frac{K_{\mathrm{He} / \mathrm{Ar}}}{1+0.012 P_{G}}$

Based on the time-temperature profiles of the EML experiments, the total mass loss and individual mass loss of each element were predicted and compared to the actual results. The data of Scancromal ${ }^{\circledR}$ and Scalmalloy ${ }^{\circledR}$ were taken from the surface tension measurements, and the data of Zicromal ${ }^{\circledR}$ were taken from an individual thermal cycle during EML processing. As seen in Fig. 12, the evaporation percentage of each element is plotted over time and superimposed with the temperature. The element $\mathrm{Mg}$ in Scalmalloy ${ }^{\circledR}$ could evaporate quickly with a superheat of $540 \mathrm{~K}$ in a short period of 45 seconds; the element Mn presents a moderate evaporation rate, and the total mass loss is $7.9 \%$ during a thermal cycle; however, its evaporation will be significantly expedited with a higher superheat of $970 \mathrm{~K}$ in the Zicromal ${ }^{\circ}$, where the total mass loss increases to over $70 \%$.

The predictions of final mass loss for each element are displayed in Table 5, the Al presents a slight loss of about 0.13 $0.15 \%$ with a superheat of $530-540 \mathrm{~K}$, and a moderate loss of $3.3 \%$ with a superheat of $970 \mathrm{~K}$; the $\mathrm{Cr}$ presents minor mass loss, and the mass loss of $\mathrm{Sc}$ and $\mathrm{Zr}$ are negligible. The predicted and actual total mass loss agrees well for each alloy. The predictions are expected to present slightly fewer values than the actual results because the cooling gas flow toward the molten droplet may blow away some of the surrounding evaporated particles and weaken the overall shielding effects, leading to a faster evaporation rate and more mass loss. The evaporation analysis is also applicable to the laser-melting or manufacturing process, and the predictions could be further improved using a non-ideal solution with accurate values of the activity coefficients of the alloy compositions.

\section{Discussion}

\subsection{Process Parameters Optimization}

In order to print as dense as possible, different process parameters were used for Scalmalloy ${ }^{\circledR}$ and Scancromal ${ }^{\circledR}$ than

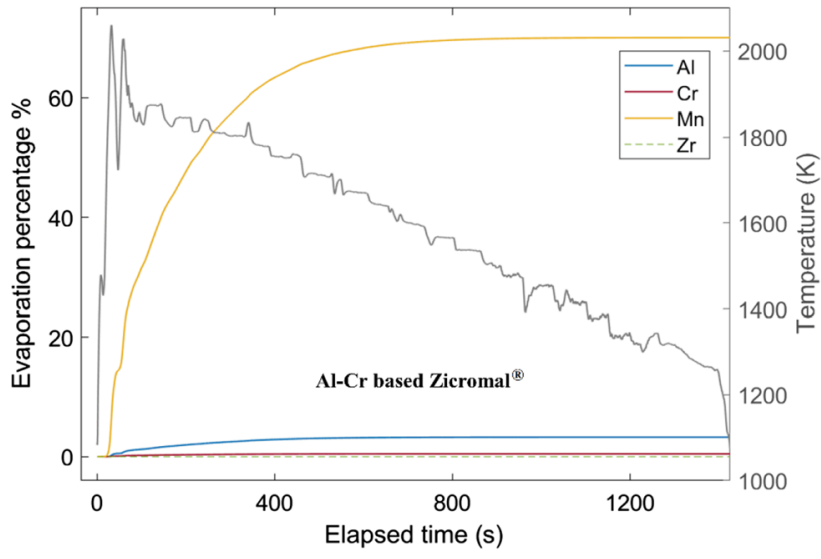

(a) Prediction of mass evaporation: Zicromal $\mathbb{\circledR}$

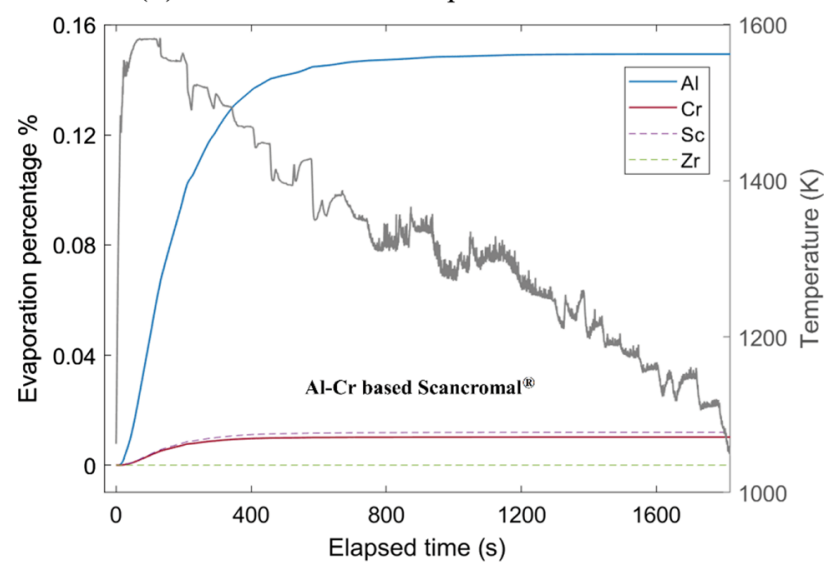

(b) Prediction of mass evaporation: Scancromal ${ }^{\circledR}$

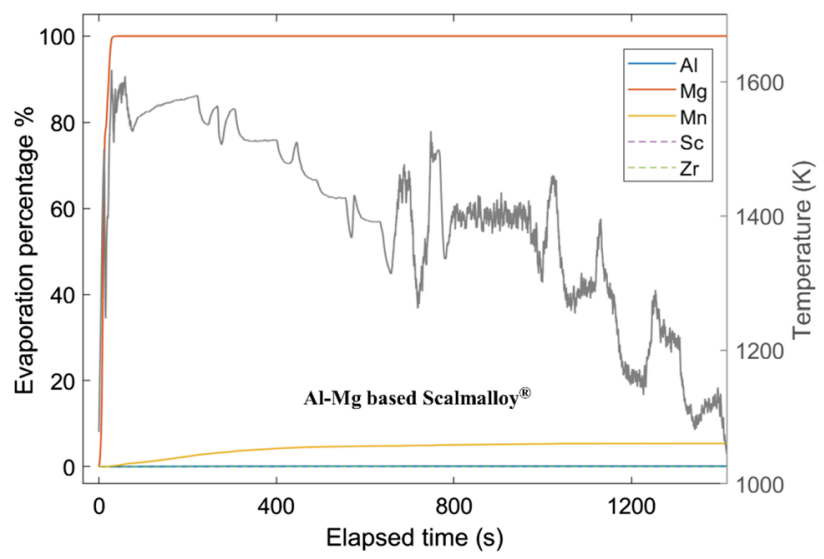

(c) Prediction of mass evaporation: Scalmalloy ${ }^{\circledR}$

Fig. 12 Predicted evaporation of EML processed alloy samples as a function of temperature and elapsed time from being melted

for Zicromal ${ }^{\circledR}$. The reasons for this are manifold. One of the reasons is the different chemical compositions of the alloys, which leads to different absorption and reflection of the laser light (also depending on the laser wavelength used), as well as different evaporation (burn-off) of low-boiling point elements (Mg for Scalmalloy ${ }^{\circledR}$ and $\mathrm{Mn}$ for Zicromal $\left.{ }^{\circledR}\right)$. Furthermore, other factors can be influenced, such as the flow velocity in the melt pool, surface tension, viscosity, welding mode, and shape of the melt pool, which can result in material defects/pores. Another reason for using different parameters to create dense 
components is the powder size distribution. For smaller powder particles (Zicromal $\left.{ }^{\circledR}\right)$, a lower power density/volume energy density is needed to melt them than larger powder particles (Scancromal ${ }^{\circledR}$ and Scalmalloy ${ }^{\circledR}$, see Table 1).

Another critical point is the cleanliness/purity of the powder. In the case of $\mathrm{Zicromal}{ }^{\circledR}$, it has been shown that a high hydrogen porosity prevails in the material, especially at low volume energy densities. By successively reducing the volume energy density (scanning faster), such problem could be eliminated. Presumably, the hydrogen was forced into the aluminum lattice, which can be detrimental to the ductility of the material.

The process parameters presented in this paper for the production of dense components can also be scaled up in terms of productivity. This means it is possible to print very dense parts by increasing the layer thickness and adjusting the power, hatch, and scanning speed accordingly, confirmed by recent parameter studies on Scancromal ${ }^{\circledR}$.

\subsection{Microstructure}

A comparison of the microstructures of the aluminum alloys examined shows that a bimodal microstructure (consisting of EG and CG) forms in Zicromal ${ }^{\circledR}$ and Scalmalloy ${ }^{\circledR}$, while epitaxial grain growth over several welding beads is evident in Scancromal ${ }^{\circledR}$. Zicromal ${ }^{\circledR}$ contains 1.4 wt.\% zirconium, a large amount of grain-refining element that does not appear to be substituted by chromium or manganese. Accordingly, the primary $\mathrm{Al}_{3} \mathrm{Zr}$ phases in $\mathrm{Zicromal}{ }^{\circledR}$ contribute to heterogeneous nucleation. Even if some zirconium were substituted, for example, by primary $\mathrm{Al}_{13} \mathrm{Cr}_{2}$ dispersoids, there would still be sufficient zirconium for heterogeneous nucleation. The numerous Al-Cr-rich phases in the fine-grain area of Zicromal ${ }^{\circledR}$ are enriched in manganese, and these are mostly primary precipitates. However, it is possible that $\mathrm{Al}-\mathrm{Cr}$-rich phases are also precipitated by the layer-by-layer remelting and the resulting heat effects such as the intrinsic heat treatment.

The Scalmalloy ${ }^{\circledR}$ microstructure has been widely studied in the literature (Ref 36 ). It is a bimodal microstructure consisting of EG and CG. The primary (semi-) coherent $\mathrm{Ll}_{2} \mathrm{Al}_{3} \mathrm{Sc}$ or $\mathrm{Al}_{3}\left(\mathrm{Sc}_{x}, \mathrm{Zr}_{1-x}\right)$ phases act as heterogeneous nuclei. Magnesium does not affect the formation of these phases. Now the question arises why Scancromal ${ }^{\circledR}$ with a scandium content of $0.72 \mathrm{wt} . \%$ (comparison: Scalmalloy®: 0.73 wt.\% scandium) does not form a bimodal microstructure, although scandium is the bestknown element for grain refinement and increasing strength (precipitation (second phase) hardening by coherent $\mathrm{Al}_{3} \mathrm{Sc}$ and $\mathrm{Al}_{3}\left(\mathrm{Sc}_{x}, \mathrm{Zr}_{1-x}\right)$ phases with an $\mathrm{L}_{2}$ crystal structure (size 2-5 $\mathrm{nm})$ ). It seems that not enough primary $\mathrm{Al}_{3}\left(\mathrm{Sc}_{x}, \mathrm{Zr}_{1-x}\right)$ phases are precipitated to contribute to heterogeneous nucleation. Contrary to the literature (Ref 37$)$, which states that chromium does not affect the phase formation of scandium and zirconium, it appears that some scandium and zirconium are incorporated into the Al-Cr phase. Previously unpublished APT (Atom Probe Tomography) investigations on a Scancromal ${ }^{\circledR}$ alloy with modified chemical composition (Al-Cr-Mo-Sc-Zr) have shown this phenomenon, which decreases the number density of the primary $\mathrm{Al}_{3}\left(\mathrm{Sc}_{x}, \mathrm{Zr}_{1-x}\right)$ phases and could be the reason for the absence of fine-grain formation in Scancromal ${ }^{\circledR}$. In Scancromal ${ }^{\circledR}$, the primary Al-Cr-rich phases also precipitate at the melt pool boundary. Possibly also due to repeated melting or passive heat effects of the underlying layers. Primary $\mathrm{Al}_{3} \mathrm{Sc}$ 
or $\mathrm{Al}_{3}\left(\mathrm{Sc}_{x}, \mathrm{Zr}_{1-x}\right)$ phases are very finely and evenly distributed in the microstructure of Scalmalloy ${ }^{\circledR}$ and Scancromal ${ }^{\circledR}$.

A correlation of the primary precipitates formed during solidification (of the different aluminum alloys) and the process dynamics during L-PBF could not be found in the literature. Since temperatures of well over $2000^{\circ} \mathrm{C}$ prevail in the laser focus and thus also in the melt pool, all phases should be in solution (melting point of $\mathrm{Al}_{3} \mathrm{Zr}$ : $1577^{\circ} \mathrm{C}$ (Ref 38), $\mathrm{Al}_{3} \mathrm{Sc}$ : $\left.1320^{\circ} \mathrm{C}(\operatorname{Ref} 39)\right)$. Therefore, it stands to reason that the precipitation processes do not contribute to the melt dynamics.

\subsection{Melt Dynamics and Welding Mode}

The reason for the increased dynamics of the welding process with Zicromal ${ }^{\circledR}$ and Scalmalloy ${ }^{\circledR}$ could be moderate keyhole welding, which, in contrast to heat conduction-mode welding (Scancromal ${ }^{\circledR}$ ), creates a vapor-filled capillary due to high power densities, which penetrates deep into the component and leads to narrow, as well as deep, melting or welding paths (Ref 40). In moderate keyhole-mode welding, the energy is supplied to the material in a concentrated form via the deep penetrating capillary and does not have to be transported to depth via heat conduction, as is the case with most conventional welding processes. Due to high scanning speeds, gas vortex effects occur, as shown in Fig. 7, leading to strong powder displacements (effects on the quality of the built material can be seen in Fig. 5). By comparing the process/melt dynamics observed from Fig. 7 (many spatters, distinct plasma plumes in case of Zicromal ${ }^{\circledR}$ and Scalmalloy $\left.{ }^{\circledR}\right)$ with the melt pool geometries from Fig. 9(d), (e) and (f), it can be assumed that for Scancromal ${ }^{\circledR}$ the L-PBF process is in heat conduction-mode and for Zicromal ${ }^{\circledR}$ and Scalmalloy ${ }^{\circledR}$ in moderate keyhole mode. The melt pools for Scancromal ${ }^{\circledR}$ tend to be shallow and semi-circular. In moderate and excessive keyhole mode, the melt pools would be much larger and deeper as the higher power densities cause the vapor-filled capillary to penetrate deeper into the component, resulting in narrow and deep weld paths. This conclusion is also supported by the fact that in heat conduction welding, the energy (power density) largely enters the material via heat conduction, whereby the thermal conductivity of the material limits the maximum weld bead depth. The weld bead width is always greater than the weld bead depth. This also seems to be the case with Scancromal® (see Fig. 9e). Scancromal ${ }^{\circledR}$ also has less thermal conductivity than Zicromal® and Scalmalloy®.

The measurement results indicate that the surface tension of the aluminum melt (Scalmalloy $\left.{ }^{\circledR}\right)$ is further reduced by adding magnesium, which are also in well agreement with Ref 28, 41. Felsing et al. (Ref 42) concluded that for Al-Mg alloys, less kinetic energy is needed for melt acceleration to overcome surface tension than pure aluminum, when adding magnesium lowers the surface tension of the melts. Therefore, the formation of spatter can be reduced when the melts present a higher surface tension and a larger Weber number.

\subsection{Evaporation}

In addition, the evaporation analysis for EML processed samples shows that the Scancromal ${ }^{\circledR}$ exhibits significantly less evaporation compared to Zicromal ${ }^{\circledR}$ and Scalmalloy ${ }^{\circledR}$. This would also fit well with our results of the melt dynamics in the L-PBF process. Zicromal@ contains Mn, exhibiting a moderate evaporation or burn-off during the L-PBF process; Scalmalloy® contains $\mathrm{Mg}$ and $\mathrm{Mn}$, exhibiting a significant burn-off effect. Furthermore, Zicromal ${ }^{\circledR}$ and Scalmalloy ${ }^{\circledR}$ would actually have even lower surface tension than the measurement results due to the elements evaporation during processing. Therefore, Scalmalloy ${ }^{\circledR}$ has the lowest surface tension and highest evaporation rate among the three alloys, causing the most unstable melt dynamics resulting in weld spatters and significant burn-off; the Scancromal ${ }^{\circledR}$ has a higher surface tension and exhibits little evaporation, leading to a more robust and stable melt dynamic with much fewer defects.

It should be noted that understanding the melt dynamics is more complex than evaluating a specific factor, or whether the $3-8 \%$ difference of the surface tension is significant enough to establish a straightforward correlation to the process disturbances (spatter, swirled powder particles, etc.). In terms of the potential dominating factors, the melt dynamics can also be influenced by the other thermophysical properties.

\subsection{Viscosity}

Viscosity could be also one of the influencing factors in the melt dynamics of the L-PBF process. Klassen (Ref 43) also describes in his dissertation a vibration model according to Berkmanns (Ref 44), which includes the viscosity of the melt pool as a damping factor. Vibrations of the capillary geometry are damped more strongly at high viscosities, and the process is stabilized. A thin-bodied melt (=low viscosity) allows strong capillary movements, which in turn leads to a resonance disaster. Low damping makes self-excitation possible in the first place. As a result, alloying elements that reduce viscosity worsen process stability and vice versa. Using the example of steel and aluminum, it could be shown that due to the approximately three times lower viscosity, process instabilities occur during laser welding of aluminum (lower seam quality), whereas steel can be welded with high process reliability. For example, aluminum has a similar viscosity at $850^{\circ} \mathrm{C}$ as water at room temperature ( $\operatorname{Ref} 41,45)$. In addition, the viscosity decreases with increasing temperature (Ref 46). Therefore, the influence of different alloying elements in the aluminum alloys on the viscosity of the melt is of great importance. The viscosity of aluminum increases, for example, through the addition of chromium and manganese (Ref 47). With Scancromal ${ }^{2}$, the melting process is probably most robust because no low-boiling point elements burn-off during the process and increase rather than decrease surface tension and viscosity. Another important property that could foster robustness improvements in the melting process seems to be the lower thermal conductivity of Scancromal ${ }^{\circledR}$ which leads to heat conduction-mode welding.

\section{Conclusion}

In this work, three aluminum alloys (Zicromal ${ }^{\circledR} \mathrm{Al}-\mathrm{Cr} 4.8$ Zr1.4-Mn1.4, wt.\%, Scancromal® Al-Cr2.6-Sc0.72-Zr0.25, wt.\%, and Scalmalloy ${ }^{\circledR}$ Al-Mg3.18-Sc0.73-Mn0.39-Zr0.3, wt.\%) were investigated with respect to processability and robustness in the L-PBF process. The surface tensions of three aluminum alloys were measured using the EML facility. In the temperature range from $T_{\mathrm{L}}+100 \approx 1180 \mathrm{~K}$ to $T_{\mathrm{L}}+500 \approx$ $1580 \mathrm{~K}$, the Al-Mg based Scalmalloy® showed a surface tension lower by $3 \%$ to $8 \%$ the other two Al-Cr based Zicromal ${ }^{\circledR}$ and Scancromal ${ }^{\circledR}$ alloys. The evaporation could 
also be influential, as the element $\mathrm{Mg}$ shows the fastest evaporation rate and $\mathrm{Mn}$ shows moderate evaporation compared to the other elements during the EML experiments. In agreement with the observations of the melt dynamics during L-PBF, the Al-Mg based Scalmalloy ${ }^{\circledR}$ formed more spatters and exhibited a significant burn-off of the elements; The Al-Cr based Scancromal ${ }^{\circledR}$ could be processed with much more robustness due to its higher surface tension and negligible evaporation. Thus, both the EML and L-PBF results indicate that the surface tension and evaporation are potentially crucial factors dominating the melt dynamics. Further investigations are necessary to specify the significance of these specific factors and evaluate the influences of other thermophysical properties (e.g., viscosity) with proper experimental and numerical validations. The results of this work will contribute to the understanding of the melt dynamics during the laser-based additive manufacturing process, as well as a demonstration of the capability of L-PBF that produces lightweight and highperformance aluminum alloys for future aerospace applications.

\section{Acknowledgments}

The author X. Xiao acknowledges the funding support from the German Academic Exchange Service (DAAD) through the program of DLR-DAAD research fellowships. The authors thank Norbert Karpen from Airbus for his essential support in recording the high-speed videos for L-PBF, Jannatun Nawer from Tufts University for the valuable discussions on evaporation modeling and Dr. Holger Schnarr from Struers $\mathrm{GmbH}$ for the beautiful etched micrographs.

\section{Funding}

Open Access funding enabled and organized by Projekt DEAL.

Open Access This article is licensed under a Creative Commons Attribution 4.0 International License, which permits use, sharing, adaptation, distribution and reproduction in any medium or format, as long as you give appropriate credit to the original author(s) and the source, provide a link to the Creative Commons licence, and indicate if changes were made. The images or other third party material in this article are included in the article's Creative Commons licence, unless indicated otherwise in a credit line to the material. If material is not included in the article's Creative Commons licence and your intended use is not permitted by statutory regulation or exceeds the permitted use, you will need to obtain permission directly from the copyright holder. To view a copy of this licence, visit http://creativecommons.org/licenses/by/4.0/.

\section{References}

1. A. Aversa, G. Marchese, A. Saboori, E. Bassini, D. Manfredi, S. Biamino, D. Ugues, P. Fino and M. Lombardi, New Aluminum Alloys Specifically Designed for Laser Powder Bed Fusion: A Review, Materials, 2019, 12(7), p 1007

2. K. Schmidtke, F. Palm, A. Hawkins and C. Emmelmann, Process and Mechanical Properties: Applicability of a Scandium Modified Al-Alloy for Laser Additive Manufacturing, Phys. Proced., 2011, 12, p 369-374

3. A.B. Spierings (2018) Powder spreadability and characterization of Scand $\mathrm{Zr}$-modified aluminium alloys processed by selective laser melting: quality management system for additive manufacturing. ETH Zurich. https://doi.org/10.3929/ethz-b-000253924

4. A.B. Spierings, K. Dawson, M. Voegtlin, F. Palm and P.J. Uggowitzer, Microstructure and Mechanical Properties of As-Processed ScandiumModified Aluminium Using Selective Laser Melting, CIRP Ann., 2016, 65(1), p 213-216

5. K.V. Yang, Y. Shi, F. Palm, X. Wu and P. Rometsch, Columnar to Equiaxed Transition in Al-Mg (-Sc)-Zr Alloys Produced by Selective Laser Melting, Scripta Mater, 2018, 145, p 113-117

6. A.B. Spierings, K. Dawson, P. Dumitraschkewitz, S. Pogatscher and K. Wegener, Microstructure Characterization of SLM-Processed Al-MgSc-Zr Alloy in the Heat Treated and Hiped Condition, Addit. Manuf., 2018, 20, p 173-181

7. A.B. Spierings, K. Dawson, T. Heeling, P.J. Uggowitzer, R. Schaublin, F. Palm and K. Wegener, Microstructural Features of Sc-and ZrModified Al-Mg Alloys Processed by Selective Laser Melting, Mater. Des., 2017, 115, p 52-63

8. J. Zhang, B. Song, Q. Wei, D. Bourell and Y. Shi, A Review of Selective Laser Melting of Aluminum Alloys: Processing, Microstructure, Property and Developing Trends, J. Mater. Sci. Technol., 2019, 35(2), p 270-284

9. X.-J. Cao, M. Jahazi, J. Immarigeon and W. Wallace, A Review of Laser Welding Techniques for Magnesium Alloys, J. Mater. Process. Technol., 2006, 171(2), p 188-204

10. M. Gieseke, C. Noelke, S. Kaierle, V. Wesling, and H. Haferkamp, Selective laser melting of magnesium and magnesium alloys, in Magnesium Technology, Springer, 2013, pp. 65-68. https://doi.org/10. 1007/978-3-319-48150-0_11

11. V. Manakari, G. Parande and M. Gupta, Selective Laser Melting of Magnesium and Magnesium Alloy Powders: A Review, Metals, 2017, 7(1), p 2

12. C. J. Smithells and E. A. Brandes, Smithells metals reference book, Butterworth, Burlington, 1992

13. S. D. Palm F, Bärtl M and M. A, New tailored high strength \& ductile al-alloys for laser powderbed fusion (LPB-F), in 11th CIRP Conference Photonic Technology, 2020

14. G. Schulz, Nanoval Process Offers Fine Powder Benefits, Met. Powder Rep., 1996, 11(51), p 30-33

15. E. Weidmann and G. Anne, Struer's Application Notes: Metallographic Preparation of Aluminium and Aluminium Alloys (2016). http://www. struers.com/default.asp?top_id=5\&main_id=24\&sub_id=176\&doc_id= 864

16. J. Brillo, G. Lohöfer, F. Schmidt-Hohagen, S. Schneider and I. Egry, Thermophysical Property Measurements of Liquid Metals by Electromagnetic Levitation, Int. J. Mater. Prod. Technol., 2006, 26(3-4), p 247-273

17. J. Brillo, Thermophysical properties of multicomponent liquid alloys. Walter de Gruyter GmbH \& Co KG, Berlin, 2016

18. L. Rayleigh et al., On the Capillary Phenomena of Jets, Proc. R. Soc. London, 1879, 29(196199), p 71-97

19. D.L. Cummings and D. Blackburn, Oscillations of Magnetically Levitated Aspherical Droplets, J. Fluid Mech., 1991, 224, p 395-416

20. K. Yao, X. Min, S. Shi and Y. Tan, Volatilization Behavior of $\beta$-Type Ti-Mo Alloy Manufactured by Electron Beam Melting, Metals, 2018, 8(4), p 206

21. D. Wu, X. Hua, Y. Ye, L. Huang, F. Li and Y. Huang, Experimental and Numerical Study of Spatter Formation and Composition Change in Fiber Laser Welding of Aluminum Alloy, J. Phys. D Appl. Phys., 2018, 51(18), p 185604

22. D. Wu, X. Hua, F. Li and L. Huang, Understanding of Spatter Formation in Fiber Laser Welding of 5083 Aluminum Alloy, Int. J. Heat Mass Transf., 2017, 113, p 730-740

23. D. Wang, S. Wu, F. Fu, S. Mai, Y. Yang, Y. Liu and C. Song, Mechanisms and Characteristics of Spatter Generation in Slm Processing and Its Effect on the Properties, Mater. Des., 2017, 117, p $121-130$

24. S.A. Khairallah, A.T. Anderson, A. Rubenchik and W.E. King, Laser Powder-Bed Fusion Additive Manufacturing: Physics of Complex Melt Flow and Formation Mechanisms of Pores, Spatter, and Denudation Zones, Acta Mater, 2016, 108, p 36-45

25. S.A. Khairallah, A.A. Martin, J.R. Lee, G. Guss, N.P. Calta, J.A. Hammons, M.H. Nielsen, K. Chaput, E. Schwalbach, M.N. Shah et al., Controlling Interdependent Meso-Nanosecond Dynamics and Defect Generation in Metal 3d Printing, Science, 2020, 368(6491), p 660-665 
26. G. Champier, Physical metallurgy of aluminium powder alloys. in AGARD, Advisory Group for Aerospace Research and Development, Agard Lecture Series No. 174 New Light Alloys (Les Nouveaux Alliages Legers). North Atlantic Treaty Organization, 1990, p 6E-1$6 \mathrm{E}-21$

27. D. Schimbäck, P. Mair, M. Bärtl, F. Palm, G. Leichtfried, S. Mayer, P.J. Uggowitzer and S. Pogatscher, Alloy Design Strategy for Microstructural-Tailored Scandium-Modified Aluminium Alloys for Additive Manufacturing, Scr. Mater., 2022, 207, p 114277

28. B. Keene, Review of Data for the Surface Tension of Pure Metals, Int. Mater. Rev., 1993, 38(4), p 157-192

29. I.F. Bainbridge and J.A. Taylor, The Surface Tension of Pure Aluminum and Aluminum Alloys, Metall. Mater. Trans. A, 2013 44(8), p 3901-3909

30. I. Langmuir, Vapor Pressures, Evaporation, Condensation and Adsorption, J. Am. Chem. Soc., 1932, 54(7), p 2798-2832

31. J. Lee and D.M. Matson, Prediction of Mass Evaporation of Fe50Co50 During Measurements of Thermophysical Properties Using an Electrostatic Levitator, Int. J. Thermophys., 2014, 35(9-10), p 1697-1704

32. J. Nawer, X. Xiao, M. SanSoucie and D.M. Matson, Effect of Mass Evaporation on Measurement of Liquid Density of Ni-Based Superalloys Using Ground and Space Levitation Techniques, High Temp. High. Press., 2020, 49, p 17-29

33. J. Nawer, S. Gosse and D.M. Matson, Tracking Evaporation During Levitation Processing of Nickel-Based Superalloys on the ISS, JOM, 2020, 72(9), p 3132-3139

34. C. Alcock, V. Itkin and M. Horrigan, Vapour Pressure Equations for the Metallic Elements: 298-2500k, Can. Metall. Q., 1984, 23(3), p 309 313

35. E. Fromm, Reduction of Metal Evaporation Losses by Inert Gas Atmospheres, Metall. Trans. A, 1978, 9(12), p 1835-1838

36. Spierings, Adriaan Bernardus Powder Spreadability and Characterization of Sc- and Zr-Modified Aluminium Alloys Processed by Selective Laser Melting, Quality Management System for Additive Manufacturing, ETH Zurich, 2018
37. S. Riva, K.V. Yusenko, N.P. Lavery, D.J. Jarvis and S.G.R. Brown, The Scandium Effect in Multicomponent Alloys, Int. Mater. Rev., 2016, 61(3), p 203-228

38. L.F. Mondolfo, Al-Zr Aluminum-Zirconium System. in Aluminum Alloys, Elsevier, 1976, pp. 413-416

39. A.B. Shubin and K. Yu Shunyaev, Thermodynamic Calculations of the Interaction of Scandium Halides with Aluminum, Russ. J. Phys. Chem. A, 2010, 84(12), p 2011-2016

40. T. Lienert, T. Siewert, S. Babu, V. Acoff and S.W.P. Specifications, ASM handbook, volume 6A: welding fundamentals and processes, ASM International Materials Park, Ohio, 2011

41. J. E. Hatch et al., Aluminum: properties and physical metallurgy. ASM International, OH (1984)

42. A. Felsing and P. Woizeschke, Influence of Magnesium on Spatter Behavior in Laser Deep Penetration Welding of Aluminum Alloys, $J$. Manuf. Mater. Process., 2019, 3(3), p 71

43. M. Klassen, Prozessdynamik und resultierende Prozessinstabilitaten beim Laserstrahlschweißen von Aluminiumlegierungen. BIAS, Bremen (2000)

44. J. Berkmanns, Steigerung der Prozessstabilität beim Laserstrahlschweißen von Aluminiumwerkstoffen mit Strahlleistungen bis $6 \mathrm{~kW}$ und Tragverhalten der Verbindungen, Universität Aachen, doctoral thesis (1997)

45. T. Forsman, Laser welding of aluminum alloys, Lulea University of Technology, doctoral thesis, (2000)

46. D. Altenpohl, Aluminum and aluminum alloys, Springer, Berlin Heidelberg, 1965

47. A. Dinsdale and P. Quested, The Viscosity of Aluminium and Its Alloys-A Review of Data and Models, J. Mater. Sci., 2004, 39(24), p $7221-7228$

Publisher's Note Springer Nature remains neutral with regard to jurisdictional claims in published maps and institutional affiliations. 